FAA-AM- $\bar{i}-25$

\title{
DEVELOPVIENT OF NEW SELECTION \\ TESTS FOR AIR TRAFFIC CONTROLLERS
}

John T. Dailey, Ph.D.

Evan W. Pickrel, Ph.D.

Federal Aviation Administration

Office of Ariation Medicine

800 Independence Avenue, S.W.

Washington, D.C. 20:91

\section{ORIGIN}

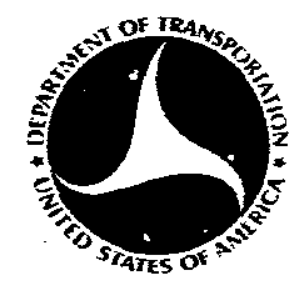

December $19 \pi$

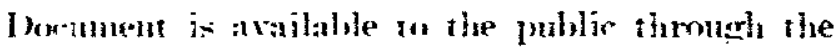

Sational Torhuinal Information service.

Springtield. Tirunia $2.21 \% 1$

Prepared for

L.S. DEPARTMENT OF TRANSPORTATION

FEDERA: AVIATION ADMINISTRATIOA

Office of Aviation Medicine

Washington, N.C. 20591 


\section{Note}

This document is disseminated under the sponsorship of the Department of Transportation in the interest of information excharige. The Cinited states Goremment assumes no liahility for it: contents or use thereof. 
Technical Keport Documentation Poge

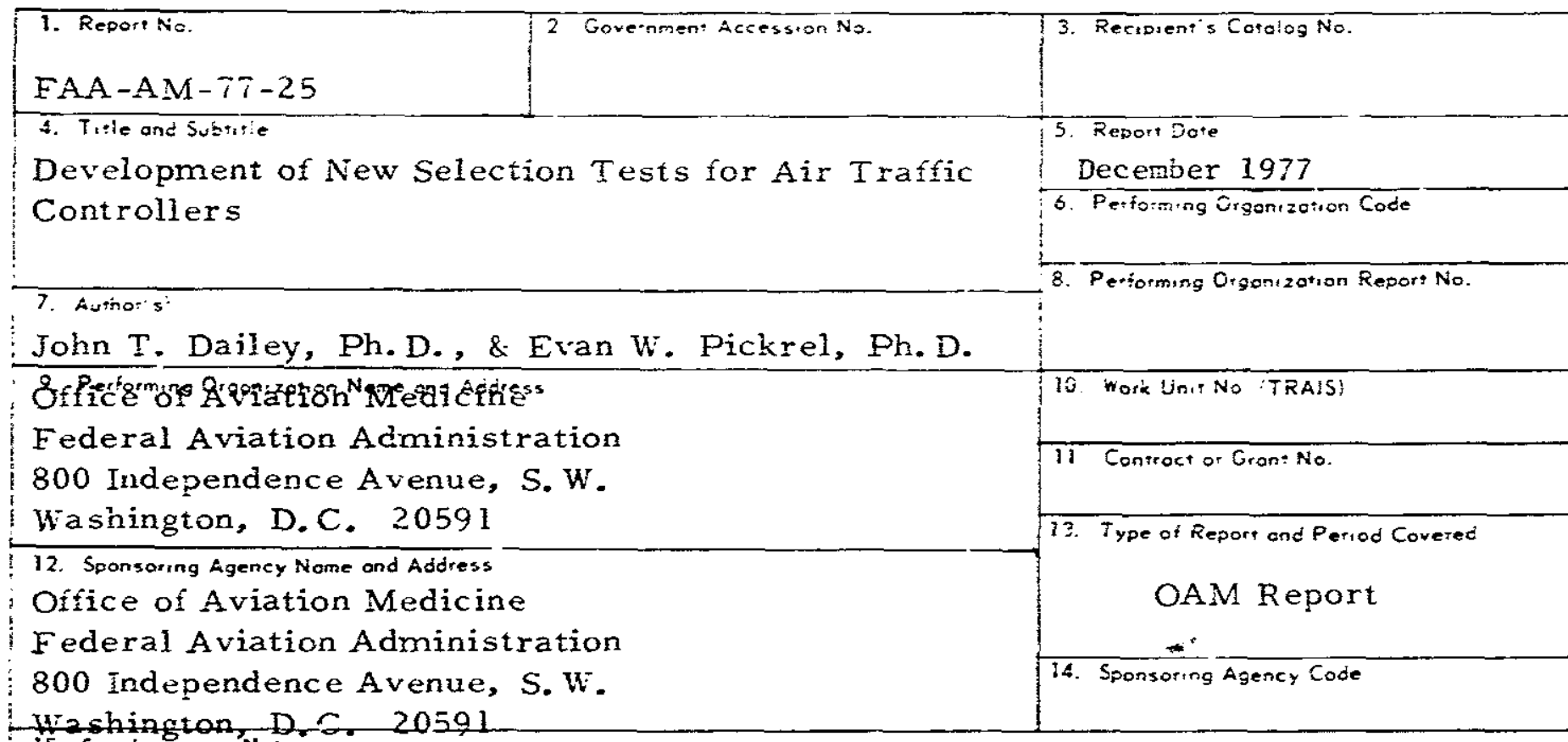

Hishington, D. S. 20591

i5. Supolementory'Notes

16. Abstract

This report describes the development of a new Multiplex Controller Aptitude Test for initial screening of FAA Air Traffic Controller applicants. Its content includes the traditional iyses of aptitude test iterns used for today's screening. In addition it includes measurement of the ability to identify potential conflicts in air traffic, a skill that has been demonstrated experimentally to have a significant relation to success in the ATC speciality. Alternate forms of the test have been developed in a format that meets Civil Service test administration requirements. The test has been administered experimentally to groips whose abilities approximate those of the applicant population, and resuits indicate that it has satisfactory reliability characteristics. It has been administered experimentally to incoming students at the FAA A IC Academy and personnel on the job at operational facilities, and constantly produced higher correlations with ATC success than any other test used in the validation siudies. The available data indirate that this new and customized instrument promises to be a significant improvement over the existing battery for screening FAA Air Trafíic Controller applicants.

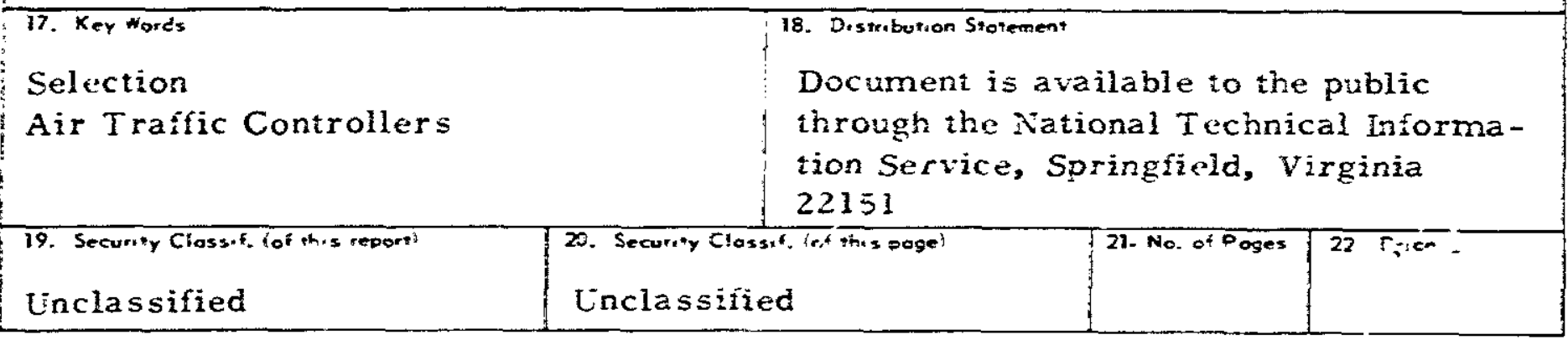




\section{DEVELOPMENT OF NEW SELECTION TESTS FOR AIR TRAFFIC CONTROLLERS}

This report clescribes creation of the Multiplex Controller Iptitude Test, a new measure to screen applicants for Federal Ariation Administration Lir Traffic Controller positions. Its content includes items to measure the iraditional types of aptitudes such as arithmetic reasoning and risualization that are included in todays Civil serrice Commission tests. In addition it includes new job sample items from the controller activity, uses figures to show air traffic on a simulated radar screen. and requires identification of potential conflicts between aircraft in that simulated traffic. All test questions are presented in an air traffic control setting. providing a job-related appearance that gires the test high face ralidity not found in today's selection battery. The format for jtem sequencing also is a departure from another current aptitude battery design practice, that of clustering items into homogeneous subgroups. Instead. in these tests the items alternate from one type to another and spiral to increasing levels of difficulty. a mode of presentation found only in a fer current tests such as the Standford-Binet. I result shown statistically is that non-confliction items included for measurement of aptitudes represented in todar's selection battery show unexpectedly hich commonality $\mathrm{x}^{\prime \prime} \mathrm{h}$ the new air traffic items requiring detection of impending conflictions. The resulting measure shows promise of consistently producing higher validity coefficients than possible with the current test battery.

\section{Background}

The current Civil Service Commission aptitude test battery for screening air traffic controller applicants has been operational since 196t. In 1970 the Federal Ariation Idministration contracted with specialists in the field of personnel selection to search for ways to alleriate problems being experienced in selection and retention of air traffic controllers. They identified other a rail- able tests to increase the predictive validity of this battery. plus areas for the construction of new tests. One of these (Buckley: Note 1) made use of a technique developed to evaluate total man-machine system performance in control of air traffic by measuring how well a fully trained specialist could control simulated traffic presented on a film using the proposed designs. In an adaption of this technique for the testing of personnel skills. films of air traffic as seen on a radar scope are presented. and observers asker? to identify the aireraft they predict will violate separation standards. This instrument added significantly to a composite for predicting onthe-job success (Milne. Note 2). but the equipment and space required for its administration generally are not arailable in Civil Service Commission testing situations. Therefore test derelopment procedures were initiated to derive measures of this same skill in a format that meets Civil service needs.

\section{Test Development}

The original Controller Decision Fraluation technique (Buckley. Note 1) required observation. of simulatef air traffic situations as ther unfold in a film of a radar scope. The observer prediets and records potential conflicts as soon as he detects them. in an unstmetured. free response mode. During experimental administration and study of three film rersions for derelopment of the Inltiplex Controller Iptitude Test, it was found that identification of potential conflict: was easier. quicker and more accurate after obsercers adjusted to the scope and its targets. when only a few targets were in near-confliction. and when their rate of closure was slow. Items were more difficult when the observers were first exposeri to the scove and its targets. when multiple targets were in near confliction and when the rate of closure amons targots was rapid. False 
positive conflict items did not discriminate and generally; for true conflicts, the greater the lead time arailable, the greater an item's discriminating power. Journeyman controllers identified potential conflicts sooner than developmental trainees, and identified almost all potentials that became real conflicts. . Developmental controllers generally missed a number of real conflicts. were slower than journeymen in calling them out. and frequently did not attend to aircraft altitude separations. Howerer. the rarge in test performance among derelopmentals was great. and some performed as well as journermen. Some confliction items in these films were too easy and some had a negative relation to a developmentaljournerman criterion dichotomy.

The observer had much idle time cluring free response film rersions of the test. as the traffic presented is light and aircraft widely separated. In this sense, the setting resembles a common air traffic situation, but an extended amount of testing time is required to present only a small number of confliction items. Better use of examinees' time was desired. In initial change during test derelopment was to stucture the items. using slides to present questions on the screen above the film. Mean response times for derelopmental and journeyman controllers to react to each conflict in the free response rersions were determiner. Journeyman mean times were selected to be determiners of aircraft positions when presenting confliction questions in the structured rersions. for this maximized the discrim ating power of each item. Two-choice conflict items. asking whether a pair of aireraft would conflict. were presented for thirty seounds when unexpecter changes occurred among targets. snch as when new aircraft entered the picture. Four-choice conflict items, asking which pair would sonflict it a confliction occurs. were presented for forty-five seconds when traffic changes were slow. I "None of these" responso was introduced to permit inclusion of non-confliction: that might be predicted to be conflictims. and this was used as the forth altemative in atl four-choice confliction items. Items were assembled into the described test format. but they didn't utilize half the arailable testing time. This large amount of idle time hetween ruestions also prorided much opportunity for ohservers to change their anwers to earlier questions regarding potential conflicts as the aircraft approached each other and the correct answers became more obvious. In the free response film version. this problem was controlled by a requirement for entries from a coded clock onio the computerscored answer sheet whenerer potentia? conflicts were reported. It was found with the paper and pencil rersion that presentation of a new item every 45 seconds would keep examinees so busy that they would have no opportunity to make such changes. More test items were needed to make this control procedure work.

The test films presented simulated traffic moving across a radar scope plus a table which includes detail data on each aircraft. identifying the target. its altitude, speed. and route on the sc se. The scope uses lines to represent airways or highways in the skT. with alphabetical identifiers of starting, ending, and intersecting points on the airways. The top of the scope is North. and a mileage scale is provided at the bottom. Imple information is presented to prepare a variety of questions related to a controller activity: It appeared possible that most factors used in the current Ciril Service Commission aptitude battery for controller selection could be measured within this simulated air traffic setting.

Items were written utilizing this arailable information to measure such aptiaudes as direction following. table rearing. interpretation of data. spatial visualization and orientation, estimation of distances and relative target movements, anci arithmetic. some items included were of a vers simple nature. and others were written in a multi-factor format to inerease their level of difficulty. For example. the directions: for this type of test required instruction on how to read the table. so initial table reading questions were included that were of the rery easy. instractional trpe. I wareness of distances across the sonpe. reading the table to determine the speeds of aircraft. and mathematical computation to determine their rates of closure (all of these heing related to horizontal separation) were rerpuired to solve a complex problem such as estimating the travel time in minutes between two aircraft at a given moment.

The reiation between item types and total test homogeneity was determined. and this ratio was used to determine the number of items per type to include in the test. I result. for example. 
was inclusion of trice as many target time-ilistance separation items as compass heading items in the test. The order of placement of conflict items had already been established by using the mean response time of journeyman controllers when targets were at certain location. New aptitude test items were placed in the remaining positions, alternating from one trpe to another and spiraling to increasing levels of difficulty as testing progressed. Three alternate forms of the test, MCAT 4, 6, and 7 , were prepared.

\section{Test Criterion Characteristics}

Versions of the fre response CODE test the structured Multiplex Controller Iptitude Test. and other selection measures were athinistered to students at the US Nary Air Traffic Controller Training School, Memphis, during the reek of Lugust 18-22, 1975. Grades of these students were obtained as they progressed through classroom and laboratory training and passed or failed the course. Distribution statistics, intercorrelations and rotated factor loadings of the various tests with each other and with school grades were determined. Forty-eight variables were involved; five factors were extracted and rotated. Definitions of the rotated factors are presented below.

Rotated Factor I. Variables with highest loadings on this factor include CTO Block I Iverage, .76, ITEX Final Criterion Exam, .54: and Control Tower Training, Airport, .53. This factor might be defined as Control Tower Operator, the title given by the school to those classroom gralles with highest loadings or portion of rariance on this factor. Imong potential screening measures, a new FAL air traffic controller ITC Occupational Knowledge Test I has the highest loading, .40 .

Rotated Factor II. Variables with highest loadings on this factor include spatial Test. .65.

Table 1

Intercorrelations of Selected Test Variables and Laboratory Grades

USN Air Traffic Control Training School

(109 Persons Tested August 18-22, 1975)

\begin{tabular}{|c|c|c|c|c|c|}
\hline Laboratory Courses & Code & $\mathrm{MCAT}$ & OKT $-I$ & $\mathrm{GCT}$ & $\begin{array}{l}\text { Arithmetic } \\
\text { Reasoning }\end{array}$ \\
\hline Laboratory Flight Plans & & $\cdot$ & & & \\
\hline VFR & 05 & 17 & 23 & 10 & 05 \\
\hline IF R & 18 & 26 & 22 & 19. & 26 \\
\hline Stopover Composite & 09 & 20 & 28 & 26 & 09 \\
\hline Performance Run & 19 & 22 & 22 & 25 & 18 \\
\hline \multicolumn{6}{|l|}{ Laboratory Control Tower } \\
\hline Basic & 16 & 20 & 28 & 19 & 21 \\
\hline Intermediate & 19 & 11 & 07 & 17 & 09 \\
\hline Advanced & 26 & 17 & 27 & 19 & 08 \\
\hline \multicolumn{6}{|l|}{ Laboratory Radar Training } \\
\hline week-1 & -02 & 10 & 11 & 17 & 10 \\
\hline Week-2 & -08 & 04 & 21 & 69 & 12 \\
\hline \multicolumn{6}{|l|}{ Precision Approach } \\
\hline week-3 & 08 & 21 & 13 & 14 & 08 \\
\hline Week-4 & 16 & 04 & 09 & 11 & 25 \\
\hline Course Average & 22 & 27 & 43 & 34 & 23 \\
\hline Free Response Code & & 43 & 32 & 12 & 14 \\
\hline MCAT & & & 42 & 20 & 23 \\
\hline \multicolumn{4}{|c|}{ ATC Occupational Knowledge } & 29 & 24 \\
\hline \multicolumn{4}{|l|}{ USN GCT } & & 31 \\
\hline
\end{tabular}


Mechanical Coniprehension, .63, and Arithmetic Reasoning, .53. This factor might be defined as Mechanical-Spatial, since the spatial and mechanical comprehension selection tests have highest loadings on this factor. This factor seems to account for very little criterion variance.

Rotated Factor III. Variables with highest loadings on this factor include Course Average, .82, Basic Lab. Control Tower Training, .65, and Stopover Composite Flight Plan Lab, .60. This factor might be defined as Laboratory Performance, since laboratory activities have their highest loadings on this factor: Imong potential screening measures, ATC Occupational Knowledge Test I and the Muitiplex Controller Iptitude Test, with loadings of .22 and .21 respectively, have the highest loadings on this factor.

Rotated Factor IV. Variables with highest loadings on this factor include Multiplex Controller Aptitude Test, .58, Free Response Code. .49, ITC Occupational Knowledge Test I. .46, Nayy General Classification Test. .40, ACT Occupational Knowledge Test II, .36. Charts \& Publications, Base Ops., .36, and Precision Approach Radar Lab., .30. This factor might be defined as Air Traffic Controller Performance. since selection tests involving the controller activity and classroom and laboratory perfornance varjables have significant loadings on this factor.

Rotated Factor V. Variables with highest loadings on this factor include Reading. .70, Radioman, .58, and Precision Approach Radar Lab., .52. This factor might be rlefined as Reading, since that variable has the highest loadings on this factor.

\section{Selected Intercorrelations}

Selected clata are presented in Table 1 to highlight three of the experimental selection tests being studied here, their interrelations with each other and with laboratory Flight Plans, Control Tower, and Radar Iraining, as those grades provide the greatest range in criterion scores for differentiating performance among $F . L$.I student controllers. ITC Occupational Knowledge Test I, a measure of each person's past controller experience. showed highest relation to performance in laboratory classes. The thirty minute Multiplex Controller Aptitude Test generally had correlations with criterion variables that are as high or higher than those between the Free Response CODE test and those same criterion rariables. These results encouraged further development of the Multiplex Test.

Table 2

Selection Test Variables and School Grades

Selected Intercorrelation Data

USAF Air Traffic Control Training School

(461 Persons Tested October 20-24, 1975)

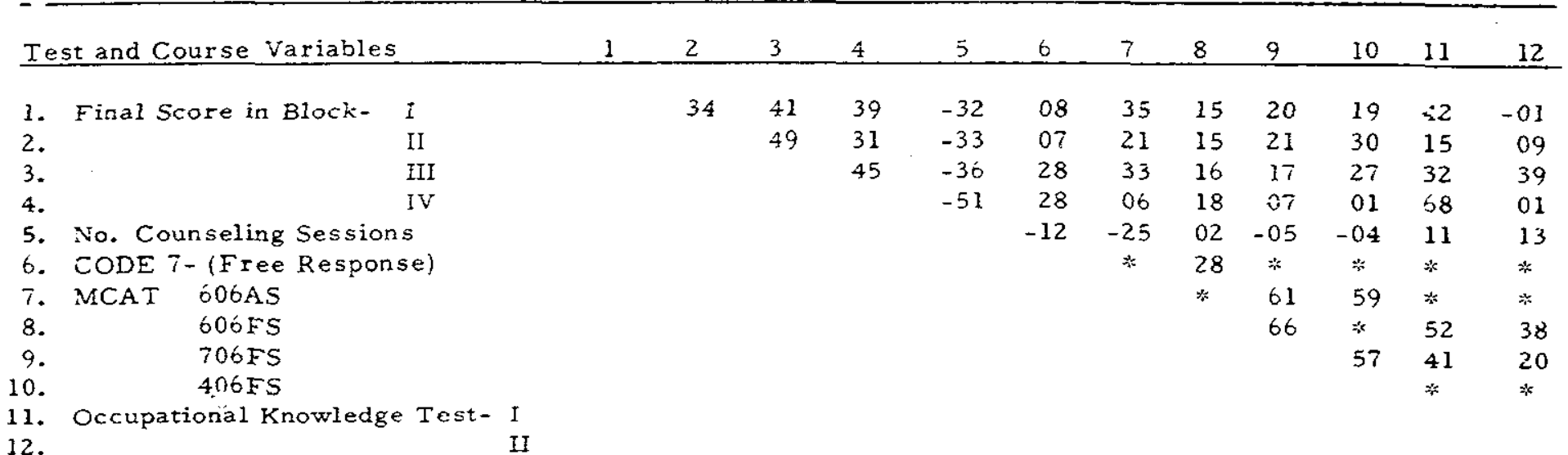

*No Cases 


\section{Media For Presenting Items}

A next step in test development was to convert the slides plus film presenting moving targets to a "slicle only" presentation. in essence capturing pictures of the scoje with targets in the same position as when each question appeared on the screen. Pacing of slide presentition was the same as in the film plus slide rersion. so the amount of target movement from question to question was unchanged. This format was easier for test administrators since they no longer had to cope with film projection problens. and the stationary targets presented by slide seened easier to read than the moving targets presented by film. Persons taking the experimental version in this slide format did arumble that the test seemed to take control orer their time. as each item had to be completed quickly hefore it left the screen and a new item appeared. This task characteristic has some commonality with controller situations in the real world. as traffic morement tends to control their involrement and pace of work. Inother merit of this rersion mould be its case for transition into a paper and pencil format that would meet Civil Service Commission requirements for us in their very secentralized field testing situations. Films plus slide and "slide only" versions of the Multiplex Controller Iptitude Test plus other selecrion measures were administered to students at the CAIF Air Traffic Controller Technical School. Keesle Lir Force Base. Mississippi. during the week of October 20-24. 1975. Grades of these stimints were obtained as they progressed hough classroon and laboratory trainiog and passed or failed the course. Distribution statistics and intercorrelations of the varions tests with school grades were determined. Twenty-one rariables were included, and selected data are presented in Table 2. ITC Occupational Knowledge Test I. a measure of the individual's past controller experience. shows highest selection test relation to final scores in training. The slide rersion of Multiplex generally shows higher correlations with the criteria. Block $I-\Pi$ Final sore. than CODF $i$ (Free Response) and the combination film-slide versions of MC.LT.

Table 3

Multiplex Controller Aptitude Test

Distribution Statistics for Various Populations

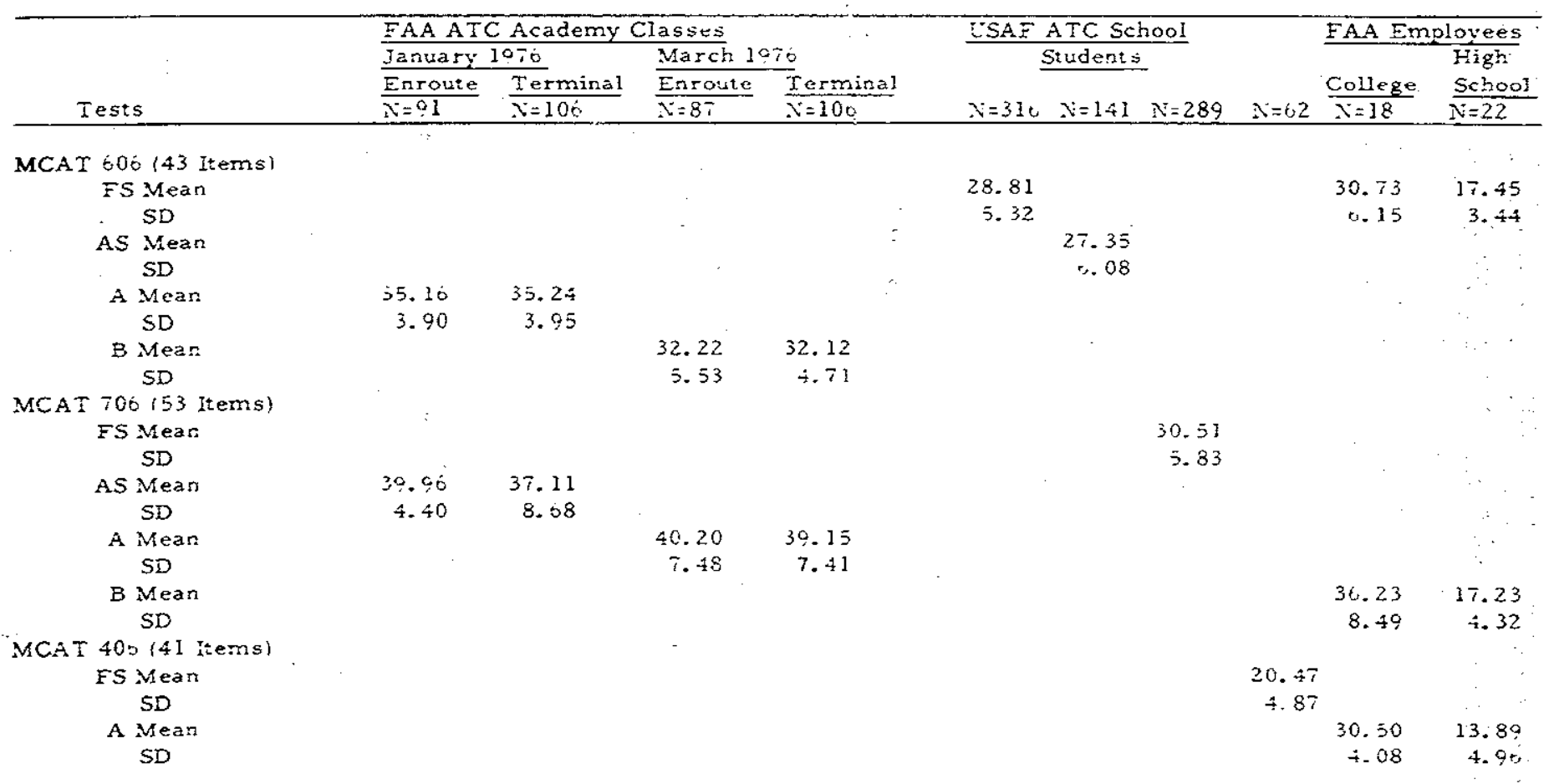

FS: Film-slide version, with time controlled for working each individual item.

AS: Slide version, with time controlled for working each individual iem.

B: Paper-and-pencil version, with time controlled for working each five-minute groip of itms. 
1 hext step in test develomment was to print the slide rersions in paper and pencil fomat. The slite rersion and combination film-slide rersion permitted time control at the individual item level, allowing thirty seconds for response to twochoice items and fory-five seconds for response to four-choice items. One palper and peneil rersion allows unintermpted work throughont testing time. with amouncements when fifteen mimutes have elapsed and when only five minutes remain to rork on the test. I segmented paper and pencil rersion allows five niinutes for response to each cluster of items presented. with a cluster containing as many as cleven items when they are all of the two-choice trpe. Three parallel forms of the written test were prepared. IICAT 406 including +1 items. 606 containing 4.3 items and 706 containing 53 items. Time limits are 2:5 minutes plus directions for IIC.IT 406 and 606 and 30 minutes plus directions for IICAT 706. Fach form now has heen extended to 5 items. MCAT $40 \%$ inciudes 23 conflict and 32 aptitude items. IIC IT 607 contains 22 conflict and 33 aptitude items. and MC.IT 707 contains 23 conflict and 32 aptitule items. Time limits are 35 minutes for each of these tests.

\section{Reliability}

The questions presented in Multiplex Controller Aptitude Test. Form 4. 6 and 7 . remained unchanged for some length of time. though the media used for presenting items changed from film to slide to paper and pencil. This change in media for presenting items has some effect on an indiridual : test performance. but all forms are qualitatively sinilar. Correlations of these parallel forms proticle a minimum estinate of the measures test-retest reliability when artministered to nembers of a similar population.

These forms have been asministered to students of the I:SAF Air Traffic Controller Technical School in all phases of training and to a sample of forty non-entroller high school and college level F:I employees. groups whose abiities approxinate those of the general population of applicants that take the Ciril Scrvice Commission tests. They also have been administered to entering F.L I Ir Traffic Controller Icademy students in the new centralized Lir Traffic Controller training program. persons selected off the top of the Civil Service Register for controller applicants. Table 3 presents distribution statistics for these groups on the rarions forms of the test. The range in test scores is highly restricted for the ATC Academy group when compared to the rarage for the more general population.

Correlations between forms mere lowest. .31 to 50. for the ITC Icademy students who had a greater restriction in range of their scores. They range from .60 to .66 for the CSAF ITC students and .87 to .90 for non-controller FAA employees whose abilities more nearly approximite that popmlation for whom the test is designed. These coefficients indicate that the test will provicle reliable measures of performance under well controlled conditions, but a combining of items from two forms would provide a more satisfactory measure to use in an operational testing situation.

\section{Test Validity}

For test validation purposes the criterion used was "success" in air traffic control work. Success as defined here for ITC applicants is hievarchical. inchuling (1) satisfactory completion of the initial. formal training program. (2) satisfactory performance on the jol. and (3) progression or upward mobility within the ITC srstem. Inother element. (4) attrition. may ie a measure of non-success. Those enrolled in the initial. formal training program are a highly select group. for they scored high enough on the Civil Serrice Commission tests to be hired. but group membership becomes even more seleclive as these who fail to learn or perform adequately are separater. This selection process continues as they progress up the ITCS career larder and are evaluated for satisfactory performance on the job and advancement into the more demanding and higher paid positions within the ITC stitem. The range in scores on these selection tests will he greatest for the group when they first enter formal training. but become ever more restrictive with career progression. Ls this restriction in range may have a direct effect on the size of the validity coeffieients. the validities should be highest when the group is in initial training and become lower for that portion of the group which progresses up the carrer ladder. 


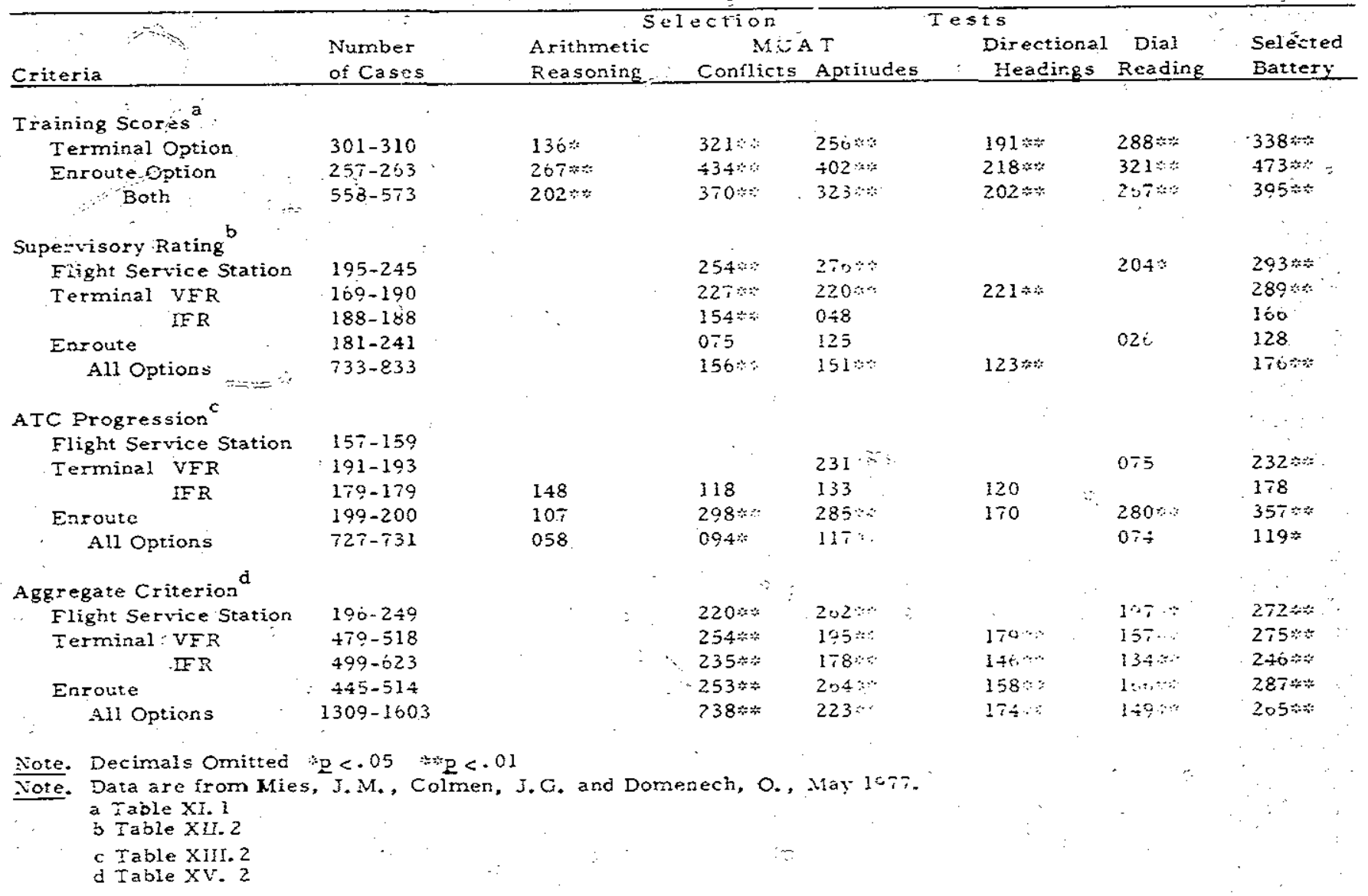

Success in Training. I battery of predictors incluting Multiplex Controller Iptitude Test 606.1 and $706 \mathrm{~A} 5$. scored separately for Conflicts and Iptitudes, plus Directional Headings, Dial Rearling and Irithmetic Reasoning tests becalner of the promise they (lemonstrated in an earlier study (Milne. Note 2), were administered to the . January 1976 Class of students entering the $\mathrm{ATC}$ Acarlemy centralized training course. Persistent mechanical problems in operation of film, slicle and slicle programmer equipment wave strong support to the Civil service Commission stated need for derelopment of these measures in a paper and pencil format. Thu the Marcli 1976 class of students were administered only paper and pencil rersions IIC.IT 706.1 and $606 \mathrm{~B}$. plus the other selection measures. Satisfactory completion of the initial. formal training program for those enrolled in the Enroute option was based on scores received on four ATC laboratory problems plus scores on a Controller Skills Test. For those enrolled in the Terminal course. performance was based only on the ITC laboratory problems. These scores require students to demonstrate operational application of academic knowledge. Correlations between selection tests and training scores are presented in Table 4 . The IIC.IT Conflict and Lutitude scores constantly produced higher alidities than any other test used. In fact addition of the other tests increased the multiple correlation by only 017 for Terminal. .012 for Enroute. and oos for both options combinerl.

Performance on The Job. Test validation in the operational sitnation. test correlation with mpervisory ratings and career progression scores. was accomplished as part of a larger LTC selection research effort (Xies. Note 3). I comprehensive sampling design was constructed to define the ITC population. constraints were rstablished. and stratified random sampling methods then applied to select the primary samples of specialists from within the total available ITC population. On-the-job performance was measured by confidential joh-task assessments prepared by each employee's superrisor. 
By ATC Option and All Options Combined

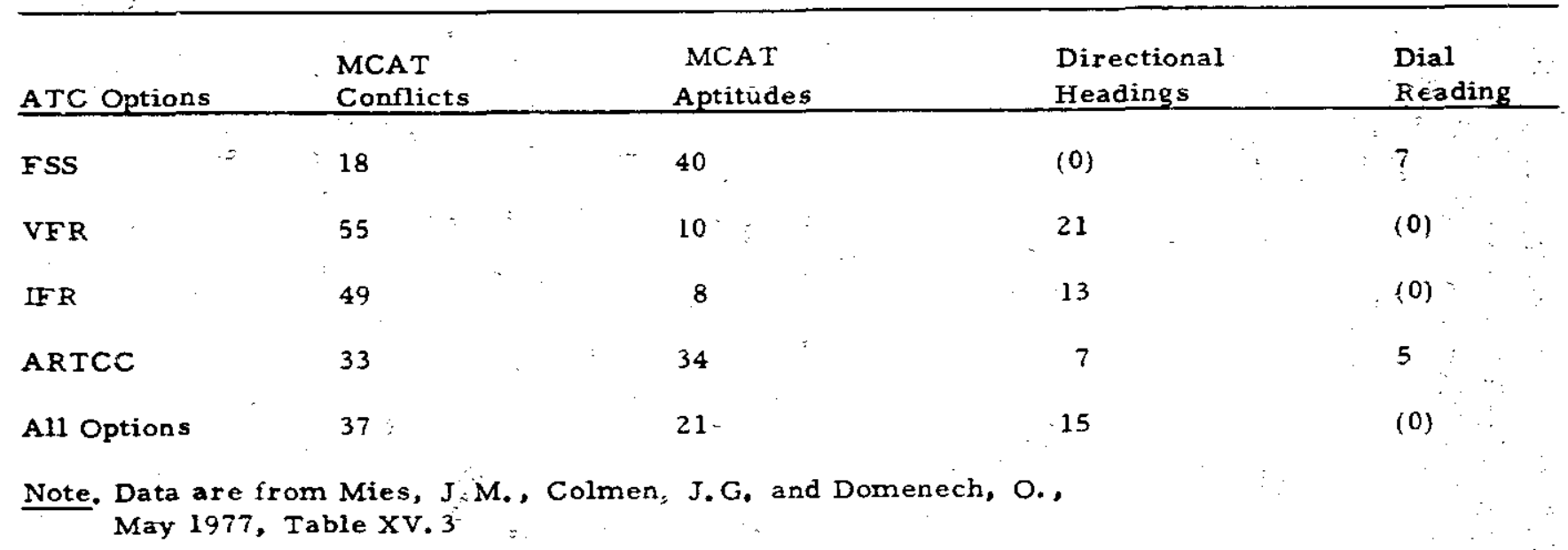

All data were collected at ATC facilities. Corvlations between selection tests and upervisory ratings are presented in Table 4. Correlation between MCAT Conflict and Iptituide scores and supervisory ratings are significant (i. $\leq .01$ ) for the FSS and Terminal VFR options and for all options combined. The correlation between MCAT Conflict scores and Teminal TFR supervisory ratings also was significant (p. $\leq .01$ ). The ICAT Conflict and A ptitude variables were prominent predictors in most regression equations which predicted job performance "success:" although neither predicted at significant levels of confidence for the Enroute option. Directional Headings appeared ralid only for the VFR option and for all options combined. Dial Reading entered for FSS only.

ATC Progression. ATC Progression was measured by comparison of the ATC option to which the specialist was initially assigned when hired to the option assigned on January 1, 1976. $\Lambda$ progression from FSS to Terminal VFR and IFR and Enroute options was used to represent levels of increasing complexity. A progression of "high" was assigned within this hierarchy when a specialist was in an option of a complexity level the same as or higher than the initial option assigned. A progression value of "Iow" was assigned when a specialist was in an option of a lower complexity level than the option to which initially assigned. Correlations between selection tests and progression scores are presented in Table 4. Again the MCAT Conflicts and Aptitudes were prominent predictors.

Aggregate Criterion. An agg egate criterion of ATC "success" was constructed from combinations of the four individual eriteria (training. on-the-job performance, progression, and attrition) and provided a five point scale value for ITC success. The Arithmetic Reasoning Test was ralid only against the progression criterion, and was dropped from the battery. The Directional Headings Test was dropped for FSS, since it failed to enter the regression for supervisory assessment. Correlations between selection tests and the aggregate criterion are presented in Table 4. All correlations are significant ( $\mathrm{p}$. $\leq .01$ ) for each of the four options and for all options combined. The Dial Reading Test did not enter the regression for the VFR option and entered last with a negative "b" weight for IFR and for all options combined. The integer weights assigned to tests are summarized in Table 5 . It is evident that MCAT (Conflict and Aptitude segments) is the major factor in the ralidities $(R)$ derived from the multiple regression analysis.

\section{Summary}

$\Lambda$ new test has been dereloped for initial screening of FAA Air Traffic Controller applicants. Its content includes the traditional types of aptitude test items found in today's Civil 
Service screening battery. In addition. it includes a measure of the ability to identify potential conflicts in air traffic. a skill that has been demonstrated experimentally to have significant relation to success in the F.I. ITC specianity. All test questions are preesnted in an air traffic control setting. which gives them a job-related appearance not found in todays selection battery. Alternate forms of the test have been developed in a paper-and-pencil format to meet Civil Serrice needs in their decentralized testing program. The test has been administered experimentally to groups whose abilities approximate those of the applicant population, and correlations between alternate forms indicate that it has satisfactory reliability characteristics. It has been administered experimentally to students entering the new F.i. ITC Acadeny and personnel on the job at operational facilities, and constantly produced higher corre- lations with ATC success than any other test used in the validation studies. The arailable dita indicate that this new and customized instrument. when used in combination with other selectert neasures, promises to be a significant improvement over the existing hattery for screening F.1.1 Air Traffic Controller applicants.

\section{Reference Notes}

1. Fuckley, E. I'. \& Batele, T. The areropment of a mốion pirture measuit nent for aptitude for air traffic (o)mtol. FA.1-LI)-71-166. Arlantic ('ity. New fersey: National dviatien Facilities Finerimultal ('entere, January 1972.

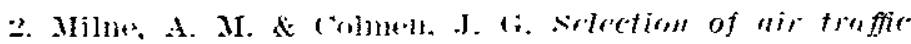

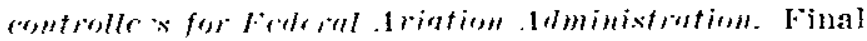

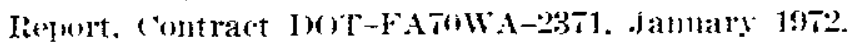

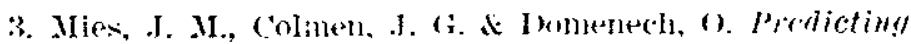

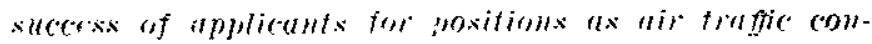

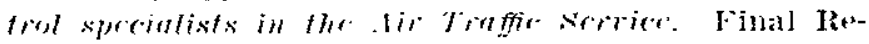

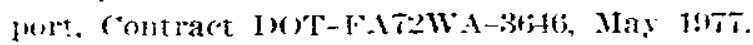

